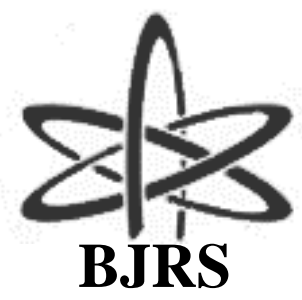

\author{
BRAZILIAN JOURNAL \\ $\mathrm{OF}$ \\ RADIATION SCIENCES \\ 08-03 (2020) 01-16
}

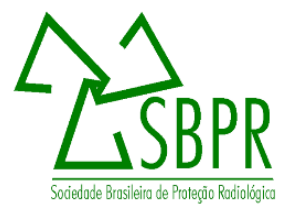

\title{
Irradiação de alimentos no Brasil: revisão histórica, situação atual e desafios futuros
}

\author{
Levy $^{\mathrm{a}, \mathrm{b}}$ D., Sordi ${ }^{\mathrm{a}}$ G.M.A.A., Villavicencio ${ }^{\mathrm{a}}$ A.L.C.H. \\ ${ }^{a}$ Instituto de Pesquisas Energética e Nucleares, São Paulo, Brasil \\ ${ }^{b}$ Omiccron Tecnologia e Informação LTDA, Atibaia, Brasil \\ denise@omiccron.com.br
}

\section{RESUMO}

O presente artigo apresenta um panorama histórico da evolução do processo de irradiação de alimentos no Brasil, analisando questões regulatórias nacionais, técnicas utilizadas e aportes nos cenários social, sanitário e econômico. Esta revisão tem por objetivo fornecer à comunidade científica uma perspectiva abrangente sobre a atual situação da irradiação de alimentos no Brasil, proporcionando novas reflexões sobre eventos passados, limitações atuais e possibilidades futuras. São analisados e discutidos atuais fatores que limitam uma mais ampla utilização da irradiação de alimentos no país, dentre os quais, a carência de irradiadores que possam atender às distintas regiões do país. Finalmente, o artigo apresenta a equivocada percepção de risco por parte da população e a necessidade de ações para impulsionar a aceitação pública, dentre as quais, o desenvolvimento de programas de comunicação e informação junto ao público leigo que desconhece as contribuições das aplicações pacíficas da tecnologia nuclear.

Keywords: tecnologia nuclear, irradiação de alimentos, aceitação pública. 


\begin{abstract}
This article presents a historical overview of the evolution of the food irradiation process in Brazil, analyzing national regulatory issues, techniques used and contributions in the social, health and economic scenarios. This review aims to provide the scientific community a comprehensive perspective on the current situation of food irradiation in Brazil, providing new reflections on past events, current limitations and future possibilities. Current factors which limit the wider use of food irradiation throughout the country are analyzed and discussed, including the lack of irradiators to serve the different regions of the country. Finally, the article presents the mistaken public perception of risk and the need for actions to boost public acceptance, including the development of communication and information programs for the population, that most often seem to be unaware of the beneficial applications of nuclear technology.
\end{abstract}

Keywords: nuclear technology, food irradiation, public acceptance

\title{
INTRODUÇÃO
}

O Brasil é um grande produtor e exportador de alimentos: soja, açúcar, café, carne de frango, carne bovina e frutas estão entre os principais produtos exportados. Entretanto, apesar da capacidade de produção de alimentos em grande quantidade, uma parcela substancial da população brasileira ainda enfrenta questões de fome, insegurança alimentar e desnutrição [1]. A questão do suprimento alimentar com quantidade, qualidade nutricional e segurança não se deve à quantidade de alimentos produzidos no país, mas sim ao baixo poder aquisitivo de grande parte da população brasileira. É sabido que, da agricultura à mesa do consumidor, grande parte dos alimentos é perdida nos processos de pós-colheita, transporte, armazenagem e comercialização, devido à deterioração dos produtos oferecidos [2]. Esses fatores contribuem para diminuição da oferta e acréscimo do preço dos produtos alimentares no mercado interno. A questão da pobreza não apenas leva grande parte da população à insuficiência da alimentação, como também à aquisição de alimentos em condições impróprias à saúde. O combate à fome e à desnutrição são duas das principais questões brasileiras [1]. Nesses quesitos, as técnicas nucleares despontam como alternativas viáveis para responder à emergência esta demanda, tanto em questões econômicas quanto de saúde pública. 
A irradiação de alimentos é uma técnica para preservação e desinfestação de alimentos, submetidos a doses controladas de radiação para eliminação de insetos ou redução de microrganismos que contribuem para deterioração e comprometem a segurança do alimento. Podem ser utilizadas fontes de ${ }^{60} \mathrm{Co},{ }^{137} \mathrm{Cs}^{1}$, raios $\mathrm{X}$ e elétrons acelerados. O processo de irradiação não deixa resíduos no alimento nem libera material radioativo no meio ambiente e todo o processo é monitorado para garantir a qualidade do alimento e preservação de suas qualidades sensoriais e nutricionais. Uma grande vantagem desta tecnologia é que pode ser realizada após o alimento já embalado, reduzindo significativamente o risco de recontaminação durante as fases de transporte, armazenamento e comércio dos produtos alimentícios.

O alimento não se torna radioativo, pois as doses são muito pequenas para provocar reações em nível atômico. A radiação ionizante, sejam partículas ou ondas eletromagnéticas, possuem energia suficiente tão somente para alterar a estrutura da matéria, na obtenção da finalidade desejada, como inibição do brotamento, atraso no processo de maturação, desinfecção de insetos, desinfecção de parasitas, redução da carga microbiana e redução de fungos. Grande parte dessas finalidades podem ser obtidas com baixas doses [3], como demonstrado na TABELA 1. Importante ressaltar que, em se tratando de irradiação de alimentos, são consideradas baixas doses aquelas até $1 \mathrm{kGy}$; médias doses acima de 1 até 10 kGy e altas doses são aquelas acima de 10 kGy.

Tabela 1 - Doses suficientes para alcançar as finalidades almejadas

\begin{tabular}{lll}
\hline Finalidade & Dose absorvida & Alimento \\
\hline Inibição do brotamento & 0,03 a $0,12 \mathrm{kGy}$ & Cebola, alho, batata \\
\hline Atraso na maturação & 0,03 a $0,12 \mathrm{kGy}$ & Cenoura, banana, morango \\
\hline Desinfecção de insetos & 0,2 a $0,8 \mathrm{kGy}$ & Pêssego, maçã, manga \\
\hline Desinfecção de parasitas & 0,1 a $3 \mathrm{kGy}$ & Ostras, marisco, salmão \\
\hline Redução da carga microbiana & 1 a $5 \mathrm{kGy}$ & Carne, frango, peixe \\
\hline Redução de fungos & 1 a $10 \mathrm{kGy}$ & Café, farinha, milho \\
\hline
\end{tabular}

Todo o processo é empreendido de acordo com as recomendações internacionais da Agência Internacional de Energia Atômica, assim como os padrões de segurança estabelecidos pelo Codex Alimentarius, Organização Mundial da Saúde (OMS) e Organização das Nações Unidas para

\footnotetext{
${ }^{1} \mathrm{Na}$ última década as fontes de césio para fins de irradiação de alimentos em escala industrial foi, aos poucos, caindo em desuso. A escolha tem sido preferencialmente por fontes de cobalto e, atualmente, há forte tendência para a escolha da irradiação por raios $\mathrm{X}$, produzidos, por exemplo, nos modernos Rodotrons.
} 
Agricultura e Alimentação (FAO), que estabelecem normas internacionais e fornecem os padrões de Boas Práticas e Avaliação de Segurança e Eficácia. No Brasil, os órgãos competentes para regulamentação e inspeção dos alimentos são: Agência Nacional de Vigilância Sanitária (ANVISA) e Ministério da Agricultura, Pecuária e Abastecimento (MAPA). A irradiação de alimentos é devidamente regulamentada no Brasil desde a década de 60, por meio de leis, decretos e normas emitidos por diversas entidades. Nas últimas décadas os avanços foram inúmeros e atualmente a irradiação de alimentos amplia as possibilidades de comércio entre países para controle fitossanitário quarentenário.

Apesar das contribuições ao mercado interno (em relação ao abastecimento alimentar e à saúde pública) e das contribuições ao comércio exterior (como medida fitossanitária no controle de pragas quarentenárias) e apesar de ser atividade prevista em lei e devidamente regulamentada, a população tem pouca ou nenhuma informação a respeito. O presente artigo tem por objetivo fornecer uma perspectiva ampla e abrangente sobre a irradiação de alimentos no Brasil, proporcionando novas reflexões sobre eventos passados, limitações atuais e possibilidades futuras.

\section{REVISÃO HISTÓRICA}

\subsection{Histórico da legislação, leis, normas, decretos e resoluções no Brasil}

A técnica da irradiação de alimentos foi introduzida na legislação sanitária do Brasil desde a década de 60 [4], no Decreto-Lei n 986/PR, de 21/10/1969, instituído pelos Ministros da Marinha de Guerra, do Exército e da Aeronáutica Militar, tendo como objetivo a defesa e a proteção da saúde individual ou coletiva, no tocante a alimentos, desde a sua obtenção até o seu consumo, em todo o território nacional. Já nesse ato legal, a irradiação de alimentos é contemplada em duas instâncias: (1) sua definição, finalidades e a instituição do Ministério da Saúde como órgão competente para elaboração de normas; e (2) indicação na rotulagem, conforme consta em seu art. 19:

"Os rótulos dos alimentos enriquecidos e dos alimentos dietéticos e de alimentos irradiados deverão trazer a respectiva indicação em caracteres facilmente legíveis."

Em 1973, é publicado o decreto presidencial $n^{\circ} 72718$, que estabelece normas gerais sobre irradiação de alimentos no Brasil [5]. O decreto regulamenta elaboração, armazenamento, transporte, 
distribuição, importação, exportação e exposição à venda ou entrega ao consumo de alimentos irradiados. $\mathrm{O}$ ato legal legitima e oficializa a utilização da técnica de irradiação, explicitando o cuidado e a seriedade com a saúde do cidadão, como exemplificado abaixo:

- Art. 3. ${ }^{\circ}$ Poderão ser utilizadas nos alimentos as irradiações ionizantes em geral, cuja energia seja inferior ao limiar das reações nucleares que poderiam induzir radioatividade no material irradiado.

- Art. 5. ${ }^{\circ}$ Somente será autorizado a irradiação de alimentos ou grupos de alimentos sobre os quais se disponha de trabalhos técnicos e científicos, desenvolvidos por instituições de pesquisa, nacionais ou internacionais, devidamente aprovados pela Comissão Nacional de Energia Nuclear (...).

- Art. 8. ${ }^{\circ}$ Os alimentos irradiados, quando expostos à venda, ou entregues ao consumo deverão trazer na respectiva embalagem e nos cartazes afixados nos locais de venda ou entrega ao consumo a indicação: "Alimento Tratado por Processo de Irradiação" e a declaração: "Este produto foi processado em estabelecimento sob controle da Comissão Nacional de Energia Nuclear".

Este Decreto, emitido pela Presidência da República em 1973, não sofre alterações ao longo dos anos e continua vigente. Sete anos depois, a Comissão Deliberativa da Comissão Nacional de Energia Nuclear - CNEN, emite a Resolução n ${ }^{\circ}$ 5/CNEN, de 10/09/1980 que aprova, em caráter experimental o Anteprojeto da Norma "Irradiação de Alimentos" [6]. O objetivo desta Norma é estabelecer as condições para o funcionamento das instalações destinadas à irradiação de alimentos, de acordo com o Decreto $n^{\circ} 72718$, de 1973. A Norma trata, pois, da Licença para Construção de instalação destinada à irradiação de alimentos, Autorização para Operação, implicações das pessoas jurídicas responsáveis e fontes de radiação permitidas, a saber: cobalto-60; césio-137; aceleradores de elétrons com energia não-superior a $10 \mathrm{MeV}$; e aparelhos emissores de raios $\mathrm{X}$ com energia nãosuperior a $5 \mathrm{MeV}$. No mais, a Norma contempla para cada fonte de radiação usada, os registros de irradiação, e indicações detalhadas para cada lote de alimentos processado (números de série, data, natureza do alimento, controles e medidas, dentre outros requisitos). Fica ainda estabelecido que a CNEN procederá as inspeções na instalação, durante as fases de construção e de operação. A Portaria $\mathrm{n}^{\circ} 59$ de 2 de junho de 1998 cancela o anteprojeto que trata especificamente do funcionamento 
das instalações destinadas à irradiação de alimentos e o tema passa a ser tratado na CNEN-NE-6 02, que dispõe sobre licenciamento de instalações radiativas [7].

Em 1985, a Portaria n 9/SVS, de 08/03/1985, relativa às áreas de alimentação e meio ambiente, aprova a relação de alimentos cuja irradiação é autorizada, indicando para cada caso: o tipo, nível e dose média e de energia de radiação que pode ser empregada, o objetivo da irradiação e o tratamento prévio, conjunto ou posterior. O documento é emitido pela Divisão Nacional de Vigilância Sanitária de Alimentos - DINAL, da Secretaria Nacional de Vigilância Sanitária do Ministério da Saúde [8]. São discutidos e aprovados neste documento os Requisitos Gerais do Processo, os requisitos tecnológicos, requisitos de qualidade, embalagem, armazenamento, rotulagem e de comercialização. Apesar de constar nas Normas Gerais uma dose média global absorvida por um alimento submetido a um processo de irradiação não superior a $10 \mathrm{kGy}$, visando assegurar a inocuidade do alimento irradiado, sob os pontos de vistas toxicológico, nutricional e microbiológico, em seu ANEXO II, a Portaria estabelece uma relação de alimentos que podem ser submetidos a tratamento por irradiação, detalhando objetivos, tipo e nível de energia e dose média aceitável em cada caso. Dentre muitos exemplos, podemos tomar a cebola (Alliam cepa L.) que, segundo a publicação, poderia ser irradiada por raios gama de ${ }^{60} \mathrm{Co}$ e ${ }^{137} \mathrm{Cs}$, a uma dose média de $0,15 \mathrm{kGy}$, com o objetivo de inibir a germinação durante o armazenamento. A lista de alimentos indicados para irradiação é vasta e para cada alimento, a publicação recomenda a observação das boas práticas e atenção às mesmas precauções higiênicas, condições de manipulação e tratamento que são adotadas para os produtos não irradiados. Este ato legal, entretanto, não está em vigência, tendo sido revogado e substituído pela Resolução n 21/ANVISA, de 26/01/2001 [9].

Efetivamente, a partir do ano 2000, várias são as publicações que trataram da irradiação de alimentos, em seus diversos aspectos: requisitos gerais, trabalhadores autorizados, instalações e objetivos diferentes daqueles inicialmente propostos. Precisamente no ano 2000, a ANVISA lança a Consulta Pública $n^{\circ}$ 83/ANVISA, de 18/10/2000 visando aprovar o Regulamento Técnico para Irradiação de Alimentos considerando o alimento, já embalado ou a granel, submetido a doses controladas de radiação ionizante, com finalidades sanitária, fitossanitária e/ou tecnológica [10]. A Resolução, que em seu artigo Art. $5^{\circ}$ revoga a Portaria no 9 - DINAL/MS, de 8 de março de 1985 e a Portaria $\mathrm{n}^{\circ} 30$, de 25 de setembro de 1989 [8] -[11], considera: 
- a necessidade de constante aperfeiçoamento das ações de controle sanitário na área de alimentos visando a proteção à saúde da população;

- a necessidade de atualizar, harmonizar e consolidar as normas e regulamentos técnicos relacionados a alimentos;

- os estudos atualizados sobre aplicação da irradiação no tratamento sanitário de alimentos.

A nova resolução reafirma e completa as orientações sobre instalações licenciadas e autoridades competentes (em âmbito municipal, estadual e federal), assim como a Comissão Nacional de Energia Nuclear, que autoriza a atividade, e o órgão competente do Ministério da Saúde, responsável pelo cadastramento. A publicação reforça ainda as boas práticas de irradiação, segurança radiológica, eficácia, capacitação do trabalhador e adequada comunicação de que o alimento foi irradiado. Nesse quesito, conforme artigo $5^{\circ}$, a indústria que irradiar alimentos deve fazer constar ou garantir que conste a indicação de que o alimento foi tratado pelo processo de irradiação nas Notas Fiscais (alimentos a granel), Notas Fiscais e embalagens (alimentos já embalados), e cartaz ou placa com a informação: "ALIMENTO TRATADO POR PROCESSO DE IRRADIAÇÃO" (nos locais de exposição e venda de produtos a granel irradiados). Quanto às fontes de radiação e suas especificidades, permanecem tal qual publicadas no Decreto de 1973 e Portaria de 1985. Quanto ao tipo de alimento, objetivos da irradiação e doses recomendadas, a ANVISA não elabora orientações específicas, como apresentava o ANEXO II da DINAL n 9. A orientação, de caráter geral, se apresenta em seu item 4.3 da seguinte forma:

"Qualquer alimento poderá ser tratado por radiação desde que sejam observadas as seguintes condições:

a. A dose mínima absorvida deve ser suficiente para alcançar a finalidade pretendida;

b. A dose máxima absorvida deve ser inferior àquela que comprometeria as propriedades funcionais e ou os atributos sensoriais do alimento."

Essas foram as bases para a aprovação e publicação da Resolução-RDC No 21 , que foi finalmente emitida em 26 de janeiro de 2001 [9]. Dadas as considerações que nortearam a revogação da Portaria $n^{\circ} 9$ - DINAL/MS, de 8 de março de 1985 e a elaboração da RDC 21, é compreensível que os relatores se abstiveram de informações detalhadas que poderiam cair em desuso ou serem rapidamente suplantadas por novos resultados de pesquisas e aplicações das radiações ionizantes. É sabido 
que no mundo globalizado as pesquisas e inovações tecnológicas avançam a passos largos, apontando novos caminhos, possibilidades e aplicações. Exemplo disso é a Resolução n ${ }^{\circ}$ 9/CONTER, de 25/04/2001 que, apesar de não mais vigente, de não se relacionar nem ser citada por nenhum outro documento, merece um olhar, por sua importância na época [12]. A referida Resolução institui e normatiza as atribuições exclusivas do Técnico e Tecnólogo em Radiologia, considerando justamente o avanço da tecnologia radiológica nos diversos setores da sua área na irradiação de Alimentos e Esterilização de Material. Ora, o foco no trabalhador vem ao encontro das recomendações da RDC $n^{\circ}$ 21/ANVISA, de 26/01/2001, que além das especificidades de técnicas e de processos, aborda a questão da capacitação e segurança radiológica [9]. Caberia a esse profissional, por exemplo, acionar e operar os equipamentos emissores de radiação; delimitar e sinalizar áreas restritas; exigir e fiscalizar o uso de dosímetros e EPI'S; monitorar com medidores portáteis; e verificar as condições de funcionamento dos equipamentos e fontes radioativas, dentre outras atribuições.

Outra evolução importante nos objetivos da técnica da irradiação de alimentos pode ser vista na Portaria $n^{\circ}$ 28/SDA, de 14/04/2004, que submete à consulta pública os procedimentos específicos para uso da radiação ionizante como tratamento quarentenário e fitossanitário, como tratamento único ou em combinação com outros tratamentos em operações de embalagem e em produtos a granel ou embalados, com o objetivo de prevenir a introdução ou disseminação de pragas, mediante a obtenção de respostas de mortandade, prevenção do desenvolvimento saudável, inabilidade reprodutiva e inativação das mesmas e desvitalização de vegetais [13]. Este documento se relaciona com a Lei $\mathrm{n}^{\mathrm{o}} 7802$, de 11/07/1989 e o Decreto $\mathrm{n}^{\mathrm{o}} 4074$, de 04/01/2002, ambas com foco na regulamentação, inspeção e fiscalização de agrotóxicos, seus componentes e afins [14] - [15] . A Portaria $\mathrm{N}^{\circ} 28$, DE 14 de abril de 2004, emitida pelo Ministério da Agricultura, Pecuária e Abastecimento [16], trata então do regulamento para habilitação e credenciamento de estabelecimentos para a realização de tratamentos quarentenários e fitossanitários, no trânsito de vegetais e suas partes, mediante a utilização de processos que fazem uso de técnicas de irradiação com radiação ionizante. Diferentemente da ANVISA que opta por publicações de caráter mais abrangente, o MAPA é específico e, em seu ANEXO V descreve as pragas alvo e as respectivas dosagens autorizadas. Finalmente, em 2011, é publicada no Diário Oficial da União a Instrução Normativa $N^{\circ}$ 9, vigente até a presente data. Este ato legal adota as diretrizes da Norma Internacional para Medidas Fitossanitárias como 
orientação técnica para o uso da irradiação como medida fitossanitária, com o objetivo de prevenir a introdução ou disseminação de pragas quarentenárias regulamentadas no território brasileiro.

A TABELA 2 apresenta um resumo dos atos legais emitidos no Brasil que tratam sobre a irradiação de alimentos e que permanecem vigentes.

Tabela 2: Atos legais que permanecem em vigor

\begin{tabular}{|c|c|c|c|c|}
\hline Ato legal & Origem & Data de publicação & Ementa & Situação \\
\hline $\begin{array}{l}\text { Decreto-Lei } n^{\circ} \\
\text { 986/PR }\end{array}$ & Poder Executivo & $21 / 10 / 1969$ & $\begin{array}{l}\text { Institui normas bási- } \\
\text { cas sobre alimentos. }\end{array}$ & $\begin{array}{l}\text { Não consta revoga- } \\
\text { ção expressa }\end{array}$ \\
\hline Decreto $n^{\circ} 72.718$ & Poder Executivo & 29/08/1973 & $\begin{array}{l}\text { Estabelece normas } \\
\text { gerais sobre irradia- } \\
\text { ção de alimentos }\end{array}$ & $\begin{array}{l}\text { Não consta revoga- } \\
\text { ção expressa }\end{array}$ \\
\hline Resolução RDC n² 21 & $\begin{array}{l}\text { Agência Nacional de } \\
\text { Vigilância Sanitária }\end{array}$ & $26 / 01 / 2001$ & $\begin{array}{l}\text { Aprova o Regula- } \\
\text { mento Técnico para } \\
\text { Irradiação de Ali- } \\
\text { mentos }\end{array}$ & Vigente \\
\hline $\begin{array}{l}\text { Instrução Normativa } \\
\text { № } 9\end{array}$ & $\begin{array}{l}\text { Ministério da Agri- } \\
\text { cultura, Pecuária e } \\
\text { Abastecimento }\end{array}$ & $24 / 02 / 2011$ & $\begin{array}{l}\text { Medidas fitossanitá- } \\
\text { rias }\end{array}$ & Vigente \\
\hline
\end{tabular}

\subsection{Escolha das fontes para a irradiação de alimentos}

A legislação regulamenta e corrobora os aportes da irradiação de alimentos em seus diversos aspectos, a saber: preservação, saúde pública e tratamentos quarentenários e fitossanitários. Entretanto, se a técnica não é amplamente utilizada em nosso país, uma das principais causas é o desconhecimento, tanto por parte da população, como dos interessados envolvidos na produção e comércio de alimentos. As leis, decretos e normas supramencionados repetem a cada vez as fontes de radiação permitidas, a saber: ${ }^{60} \mathrm{Co} ;{ }^{137} \mathrm{Cs}$; aceleradores de elétrons com energia não-superior a $10 \mathrm{MeV}$; e aparelhos emissores de raios X com energia não-superior a $5 \mathrm{MeV}$. Essas orientações, estabelecidas, porém não explicadas, suscitam dúvidas e incertezas.

Com efeito, duas das principais radiações utilizadas são os raios X e gama, isto é, radiação eletromagnética como a luz solar, porém com comprimento de onda muito menor e, portanto, com muito mais energia. A radiação eletromagnética é uma escolha porque não possui a capacidade de produzir reações nucleares e, portanto, não altera as propriedades físicas e químicas do produto irradiado. A quantidade de radiação que incide e é absorvida por um alimento tem um limite, pois 
assim como a radiação solar recebida em excesso por um indivíduo produz queimaduras de primeiro, segundo e terceiro grau, a radiação em quantidade excessiva pode modificar as propriedades do alimento de maneira não desejada. Por esta razão, existem determinados intervalos de quantidades de radiação para cada tipo de alimento, em virtude de suas características naturais, e também da finalidade almejada.

No caso da irradiação de alimentos para a redução da carga microbiana, como é o caso das especiarias particularmente, são irradiados grandes volumes com as especiarias já embaladas para transporte e os volumes chegam a medir $1 \mathrm{~m}^{3}$, dependendo do tipo de equipamento utilizado para o processo de irradiação. Nesses casos em que os volumes são grandes, a densidade é considerada como a da água, igual a 1. A radiação gama é monoenergética na dexitação do núcleo do átomo, mas dificilmente encontramos emissores com energias próximas de $4 \mathrm{MeV}$. Por esta razão são escolhas possíveis para a finalidade de irradiação de alimentos:

${ }_{27}^{60} \mathrm{Co}$ - Cobalto-60: possui 2 raios gama com rendimento de $100 \%$ cada por dexitação do núcleo com energias respectivamente de $1,17 \mathrm{MeV}$ e 1,33 MeV e com uma meia-vida de 5,26 anos.

${ }_{55}^{197} C s$ - Césio-137: possui um raio gama de $0,66 \mathrm{MeV}$ com rendimento de $100 \%$ por dexitação do núcleo com uma meia-vida de 30 anos. Essas fontes são, entretanto, cada vez menos utilizadas nos processos industriais de irradiação de alimentos [16].

Outra opção viável para a irradiação de alimentos são os raios X. A vantagem do uso dos raios $\mathrm{X}$ é que existem aceleradores de partículas que produzem raios $\mathrm{X}$ de energias grandes e, portanto, podemos chegar muito próximos dos $10 \mathrm{MeV}$, nosso limite energético de feixe de radiação útil. Diferentemente dos raios gama, o acelerador é uma fonte de radiação que pode ser desligada, o que alguns consideram uma vantagem. A radiação proveniente de elétrons acelerados tem baixo poder de penetração, irradiando o alimento até alguns centímetros abaixo da superfície. O feixe de elétrons pode ser eficaz na irradiação de alguns tipos de alimento, como por exemplo: sementes, flores comestíveis, hamburgueres e filés de frango. Existem diferentes tipos de aceleradores de elétrons, dependendo de sua energia $(\mathrm{MeV}$ ou $\mathrm{KeV})$, da sua corrente $(\mathrm{mA})$ e potência $(\mathrm{kW})$ que determinarão a taxa de transferência do produto. Assim, a utilização de fonte única, ou duplas de feixes de elétrons de $10 \mathrm{Mev}$, será definida de acordo com diferentes espessuras do produto (densidade de área). Uma possibilidade para um futuro próximo é a utilização de aceleradores de tamanhos menores e a preço mais acessível, que permitirão a utilização dos feixes de elétrons para alimentos que 
demandam radiação com baixo poder de penetração e o aproveitamento dos raios X para finalidades que demandam alto poder de penetração, atravessando o alimento por inteiro.

Foram muitos os avanços tecnológicos nas últimas décadas e muitos os benefícios da irradiação de alimentos. Entretanto no Brasil, com a desinformação de produtores, indústria, comerciantes e consumidores, a irradiação de alimentos em escala industrial ainda caminha a passos lentos.

\subsection{Irradiação de alimentos para fins comerciais e industriais no Brasil}

A técnica da irradiação de alimentos foi introduzida no Brasil na década de 60. Durante as décadas posteriores, as pesquisas sobre irradiação de alimentos proporcionaram avanços em escala mundial. Desde 1974 o IPEN possui equipamentos para irradiação (tanto ${ }^{60} \mathrm{Co}$ como acelerador de elétrons), desenvolvendo e assessorando produtores com pesquisas e testes de seus produtos em uma escala semi-industrial em alimentos e produtos agrícolas.

Com o transcorrer dos anos, as exigências do mercado consumidor impulsionaram o comércio de alimentos na busca de técnicas mais saudáveis. Os novos paradigmas de cuidados à saúde clamavam pela preservação e segurança do alimento, mantendo o máximo de suas características nutricionais e sensoriais, com pouco ou nenhum dano em seus biocompostos naturais. Desde então, o processamento por radiação cresce no Brasil e no mundo [18].

O primeiro irradiador comercial foi implantado em São Paulo pela EMBRARAD em 1980. A empresa iniciou suas operações para diversos ramos da indústria, incluindo a área médica e farmacêutica, irradiação de alimentos e produtos para a agroindústria de alimentos. Em 1999, a EMBRARAD inaugurou seu segundo irradiador. Outra indústria de irradiação se estabeleceu em São Paulo em 1999, a CBE (Companhia Brasileira de Esterilização) com um irradiador de ${ }^{60}$ Co construído com tecnologia brasileira, também com a mesma finalidade da EMBRARAD. Em 2002, iniciou-se a irradiação comercial com aceleradores de elétrons. Em 2015 todos irradiadores comerciais de alimentos foram comprados pela Sterigenics, uma multinacional canadense. Até a presente data, a Sterigenics detém o monopólio da irradiação de alimentos em escala industrial no Brasil. 


\section{DISCUSSÃO}

O Brasil ainda investe em grande parte na preservação dos alimentos fazendo uso de agroquímicos e inseticidas que sabidamente deixam resíduos nos alimentos [19]. O tratamento com produtos químicos promove a resistência dos insetos e microrganismos patógenos, libera resíduos no meio ambiente, podendo ainda comprometer o equilíbrio ecológico e a saúde do trabalhador. A irradiação de alimentos apresenta vantagem em todos esses quesitos, podendo ser utilizada em muitos casos como alternativa ou conjuntamente com outros tratamentos de medidas fitossanitárias [16], [20]. Entretanto, no Brasil, a técnica não é amplamente utilizada.

Um primeiro ponto de discussão é a escassez de irradiadores que atendam em escala comercial este país com dimensões continentais. O Brasil é um dos 5 maiores países do globo, o maior país da América Latina e um dos países mais populosos do mundo. O país tem 8,5 milhões de quilômetros quadrados, divididos geopoliticamente em 5 regiões, com 3 fusos horários e conta com 26 estados e Distrito Federal. Como vimos, até os dias de hoje apenas uma empresa na região sudeste oferece o serviço de irradiação de alimentos em escala industrial. Fica claro que uma única instalação não atende às demandas de um mercado produtor espalhado nas diversas regiões do país onde, além da grande distância entre estados, conta com um sistema de transporte predominantemente rodoviário. Seria preciso o investimento na construção de irradiadores nos diferentes estados, para que se possa tratar os alimentos antes de serem transportados durante dias pelos caminhões, evitando perdas desnecessárias sobretudo durante as fases de transporte rodoviário e armazenamento. Uma vantagem da irradiação de alimentos - em nível nacional - é que, uma vez construídas as instalações, o custo desta técnica no longo prazo é bastante baixo, comparado ao tratamento com agroquímicos.

Porém, há um fator complicador para a implantação da técnica de maneira ampla e efetiva: a quase total desinformação da população, incluindo produtores, indústria, comércio e público consumidor. Sobretudo este último, cuja percepção de risco é prejudicada por preconceitos e medos infundados sobre as radiações, levando as pessoas a falsas conclusões, associando a radiação ionizante a riscos ambientais, perigo à saúde ou contaminação do alimento. Com efeito, uma pesquisa presencial realizada na capital de São Paulo, uma das maiores do país, traz resultados 
preocupantes [21]. 55\% dos entrevistados associou radiações ionizantes a guerras, contaminação, acidentes nucleares, doenças, cânceres ou mortes. $67 \%$ dos entrevistados alegaram nunca ter visto o símbolo da Radura e os $21 \%$ que alegaram reconhecer o símbolo, não sabiam o que representava. No geral, os entrevistados não sabiam a diferença entre "alimentos irradiados" e "alimentos contaminados" e confundiam "alimento irradiado" com "alimento radioativo". Ao final da entrevista, os entrevistados receberam uma brevíssima explicação sobre esta técnica de preservação para eliminar insetos e reduzir microrganismos causadores de doenças. Convidados a responder novamente sobre suas intenções de compra de alimentos irradiados, as opiniões mudaram significativamente: $70 \%$ respondeu que compraria esses alimentos, informaria a amigos e parentes e sugerira a compra para outras pessoas. A pesquisa é repetida a cada ano com novos respondentes e a experiência se repete. $\mathrm{O}$ medo por parte da população deve-se, sobretudo, à falta de informação acessível, confiável e cientificamente correta.

A ampla implantação da técnica da irradiação de alimentos no Brasil depende, pois, desses dois fatores igualmente importantes: da oferta de instalações que atendam em escala industrial os diversos estados do Brasil e de uma comunicação efetiva junto à população em todas as suas esferas.

\section{CONSIDERAÇÕES FINAIS}

O Brasil é um grande produtor e exportador de alimentos, porém uma parcela substancial da população brasileira ainda enfrenta questões de fome, insegurança alimentar e desnutrição. A irradiação de alimentos é uma das alternativas viáveis que vem ao encontro da demanda social brasileira de abastecimento de alimentos com quantidade e segurança, além do combate ao desperdício. A irradiação de alimentos contribui para a redução das perdas no pós-colheita, transporte e armazenamento, prolongando o tempo de prateleira, reduzindo o desperdício de alimentos no mercado e na casa do consumidor. A irradiação de alimentos responde também a uma demanda de saúde pública, como medida preventiva para a redução dos riscos causados por agentes patogênicos causadores de surtos alimentares e danos à saúde humana. Nesse quesito, as medidas preventivas incluem a eliminação de insetos e larvas ou redução de microrganismos indesejáveis a níveis apropriados para o consumo humano. Responde ainda a uma demanda econômica, tornando 
o país competitivo diante do mercado externo, uma vez que em muitos casos a irradiação de alimentos para fins fitossanitários é uma exigência para a exportação de frutas e carnes [16], [22]. Diante de todas essas questões, a irradiação de alimentos é uma necessidade e um desafio. Se por um lado a irradiação de alimentos pode contribuir para responder a algumas das demandas sociais, econômicas e sanitárias do país, por outro lado isso só seria possível com a implementação de diversas instalações radiativas em diversos estados, com a capacidade de irradiar alimentos em escala industrial.

Para além do desenvolvimento tecnológico, é necessário ainda investir na aceitação pública, uma vez que um dos grandes entraves em relação às técnicas nucleares é a percepção equivocada do público leigo em relação à percepção de risco das radiações ionizantes, notadamente em relação aos efeitos maléficos à saúde humana [23] - [24]. Pesquisas realizadas na década de 80, em diversos países na América, África, Ásia e Europa demonstram que programas de informação e comunicação à população influenciam a confiança no processo e as intenções de compra do consumidor e que o envolvimento da mídia, de organismos governamentais e das agências reguladoras potencializam a aceitação pública [25].

No Brasil, faz-se necessário um maior envolvimento da esfera pública, no sentido de rever e completar a regulamentação, além de promover o treinamento de pessoal apto à fiscalização. A complementação da regulamentação é essencial para conferir transparência e confiabilidade no processo, por parte do público, do mercado de alimentos e dos processos de fiscalização. Toma-se como exemplo a RDC $n^{\circ}$ 21/ANVISA, ainda vigente, que substitui a DINAL $n^{\circ}$ 9/SVS, suprimindo a relação de alimentos que podem ser submetidos a tratamento por irradiação, detalhando objetivos, tipo e nível de energia e dose média aceitável em cada caso. Hoje essa relação oficial apenas pode ser obtida por meio de publicações internacionais [3],[8],[9]. A atuação ativa de organismos reguladores pode fortalecer a aceitação de tecnologias inovadoras e conferir segurança ao processo. Apenas com amplas ações de educação à população, a irradiação de alimentos deixará de representar uma ameaça e poderá oferecer todo o seu potencial de contribuições no combate à fome e redução do desperdício, na segurança do alimento e saúde pública, no fortalecimento do mercado interno e do comércio exterior. 


\section{REFERÊNCIAS}

[1] Maitra C. A review of studies examining the link between food insecurity and malnutrition. Technical Paper. Food and Agriculture Organization of the United Nations FAO, Rome, 2018.

[2] Lana M. M. Perdas e Desperdicio de Hortaliças no Brasil In: Perdas e desperdício de alimentos: estratégias para redução. Câmara dos Deputados, Edições Câmara, Brasília, 2018.

[3] Food and Agriculture Organization of the United Nations - FDA. 21CFR179.26 in US Code of Federal Regulations, Title 21, Volume 3. Revised as of April 1, 2019.

[4] BRASIL. Decreto-Lei n ${ }^{\circ}$ 986/PR, de 21 de outubro de 1969. Institui normas básicas sobre alimentos.

[5] BRASIL. Decreto n 72718 , de 29 de agosto de 1973. Estabelece normas gerais sobre irradiação de alimentos.

[6] Comissão Nacional de Energia Nuclear - CNEN. Resolução n 5 de 10 de setembro de 1980. Aprova em caráter experimental a Anteprojeto da Norma Irradiação de Alimentos.

[7] Diario Oficial da União - D.O.U. Seção 1, Edição 107, 8 de junho de 1998, pp 8.

[8] Divisão Nacional de Vigilância Sanitária de Alimentos - DINAL. Portaria $\mathrm{n}^{\circ}$ 9/SVS, de 08 de março de 1985. Aprova a Relação de Alimentos cuja irradiação é autorizada, indicando para cada caso: o tipo, nível e dose média de energia de radiação que pode ser empregada, o objetivo da irradiação e o tratamento prévio, conjunto ou posterior.

[9] Agência Nacional de Vigilância Sanitária - ANVISA. Resolução RDC no 21, de 26 de janeiro de 2001. Aprova o Regulamento Técnico para Irradiação de Alimentos.

[10] Agência Nacional de Vigilância Sanitária - ANVISA. Consulta Pública nº 83/ANVISA, de 18 de outubro de 2000

[11]Divisão Nacional de Vigilância Sanitária de Alimentos - DINAL. Portaria $\mathrm{n}^{\circ} 30$, de 25 de setembro de 1989. Autoriza o uso de tratamento por irradiação a determinados alimentos.

[12] Conselho Nacional de Técnicos em Radiologia - CONTER. Resolução n 9/CONTER, de 25 de abril de 2001. Institui e normatiza as atribuições exclusivas do Técnico e Técnólogo em Radiologia na área de Irradiação de Alimentos e Esterilização de Material.

[13] Ministério da Agricultura, Pecuária e Abastecimento - MAPA. Portaria n 28/SDA, de 14/04/2004, Submete à consulta pública, por um prazo de 60 (sessenta) dias, que dispõe sobre os procedimentos específicos para uso da radiação ionizante como tratamento quarentenário e fitossanitário, como tratamento único ou em combinação com outros tratamentos em operações de embalagem e em produtos a granel ou embalados, com o objetivo de prevenir a introdução ou disseminação de pragas, mediante a obtenção de respostas de mortandade, prevenção do desenvolvimento saudável, inabilidade reprodutiva e inativação das mesmas e desvitalização de vegetais.

[14]BRASIL. Lei $n^{\circ} 7802$, de 11 de julho de 1989. Dispõe sobre a Pesquisa, a Experimentação, a Produção, a Embalagem e Rotulagem, o Transporte, o Armazenamento, a Comercialização, a Propaganda Comercial, a Utilização, a Importação, a Exportação, o Destino Final dos Resíduos e Emba- 
lagens, o Registro, a Classificação, o Controle, a Inspeção e a Fiscalização de Agrotóxicos, seus Componentes e Afins, e dá outras Providências.

[15]BRASIL. Decreto ${ }^{\circ}$ 4074, de 04 de janeiro de 2002. Regulamenta a Lei no 7.802, de 11 de julho de 1989, que dispõe sobre a pesquisa, a experimentação, a produção, a embalagem e rotulagem, o transporte, o armazenamento, a comercialização, a propaganda comercial, a utilização, a importação, a exportação, o destino final dos resíduos e embalagens, o registro, a classificação, o controle, a inspeção e a fiscalização de agrotóxicos, seus componentes e afins, e dá outras providências.

[16] Ministério da Agricultura, Pecuária e Abastecimento - MAPA. Instrução Normativa No 9, de 24 de fevereiro de 2011. Adota as diretrizes da Norma Internacional para Medidas Fitossanitárias NIMF $n^{\circ} 18$ como orientação técnica para o uso da irradiação como medida fitossanitária com o objetivo de prevenir a introdução ou disseminação de pragas quarentenárias regulamentadas no território brasileiro.

[17] International Atomic Energy Agency IAEA, Dosimetry for Food Irradiation in Technical Reports Series No. 409, Viena, 2002.

[18]Kume,T., Furuta, M., Todoriki, S., Uenoyama, N., Kobayashi, Y. Status of food irradiation in the world in Radiation Physics and Chemistry Vol.78, 222-226, 2009.

[19]Agência Nacional de Vigilância Sanitária - ANVISA. Resolução RDC nº 295, de 29 de julho de 2019. Dispõe sobre os critérios para avaliação do risco dietético decorrente da exposição humana a resíduos de agrotóxicos, no âmbito da Anvisa, e dá outras providências.

[20]Centro de Gestão e Estudos Estratégicos (CGEE); Estudo da Cadeia de Suprimento do Programa Nuclear Brasileiro - Panorama - Análise de oportunidades e desafios para o segmento de Irradiadores e Aplicações na Cadeia Produtiva do Agronegócio, Brasília, Novembro, 2010

[21]Levy, D., Sordi, G.M.A.A., Villavicencio, A. Construindo pontes entre ciência e sociedade: divulgação científica sobre irradiação de alimentos in Brazilian Journal of Radiation Sciences, Vol 6, No1, 2018.

[22] Eustice R. F. Acceptance, use of food irradiation reached new levels in 2017, 2018. Avaiable at: $\quad$ http://www.foodsafetynews.com/2018/01/acceptance-use-of-food-irradiation-reached-newlevels-in-2017/\#.WsklbYjwbDc Last accessed: 30 June 2020.

[23] Guimarães L. S. O desafio da aceitação pública da energia nuclear in Revista Marítima Brasileira Volume 135 n. 10/12 pp.115-116, 2015.

[24]Behrens J. H., Barcellos M. N., Frewer L. J., Nunes T. P., Landgraf M. Brazilian consumer views on food irradiation in Innovative Food Science and Emerging Technologies, vol.10 383-389, 2009.

[25] Bruhn C. M. Consumer Attitudes and Market Response to Irradiated Food in Journal of Food Protection, Vol. 58. No.2 Pages 175·181, 1994. 